\title{
Pulmonary uptake in 67-gallium citrate scintigraphy-the 'negative heart' sign
}

\author{
S.G. Cooke, E.R. Davies and Paul R. Goddard
}

Imaging Research Unit, Department of Radiodiagnosis, Bristol Royal Infirmary and University of Bristol, Bristol $B S 28 H W, U K$.

\begin{abstract}
Summary: Diffuse pulmonary uptake in 67-gallium citrate (67-Ga) scintigraphy occurs in a large number of neoplastic and inflammatory conditions. Discrimination between normal and abnormal 67-Ga uptake over the chest can be difficult and a simple visual method for identifying abnormal studies is described. A series of 39 gallium scintigrams was retrospectively reviewed by the authors and reported without knowledge of the patients' clinical condition. Subsequent clinical follow up was obtained to establish the accuracy of the scintigram interpretation. Comparison of pulmonary uptake with that over the cardiac area is recommended as a simple and reliable method of confirming that the level of pulmonary activity is abnormal. In highly abnormal cases the cardiac area is seen as a 'negative heart' image due to the considerably increased activity in the lungs. This sign is best seen with abnormal diffuse uptake but is also seen with abnormal focal uptake. Care must be taken, as the sign may be masked, if uptake over the cardiac area itself is increased.
\end{abstract}

\section{Introduction}

Uptake of 67-gallium citrate (67-Ga) with diffuse or focal distribution has been documented to occur in pneumonia, sarcoidosis, cryptogenic fibrosing alveolitis, allergic alveolitis and a variety of other pulmonary inflammatory and neoplastic conditions. ${ }^{1-3}$ The exact mechanism for the Ga uptake is obscure but several explanations have been proposed. These include uptake of $\mathrm{Ga}$ by leucocytes ${ }^{4}$ and bacteria $^{5}$ and plasma protein binding by transferrin, lactoferrin and haptoglobin. ${ }^{6.7}$ From this latter explanation $\mathrm{Ga}$ uptake in tissues would be expected to reflect the distribution and activity of iron and thus it is with this element that $\mathrm{Ga}$ forms a "biological analogue'. This accounts for normal sites of uptake (particularly liver, spleen, bone marrow and gastrointestinal tract) and offers further explanation for abnormal uptake in neoplastic or inflammatory disease where iron metabolism may be disturbed.

In normal patients after $67-\mathrm{Ga}$ scintigraphy there is a low but detectable level of activity over the lungs and difficulty in interpretation can arise in discriminating between normal uptake and a slight generalized and diffuse increase in pulmonary uptake. This can particularly be a problem with less experienced observers when different intensities of hardcopy images are recorded or if larger doses of $67-\mathrm{Ga}$ are used.

Correspondence: P.R. Goddard, BSc., M.D., F.R.C.R., D.M.R.D.

Accepted: 4 July 1989
A series of consecutive $67-\mathrm{Ga}$ scintigrams was assessed visually to determine the normal acceptable pulmonary uptake, discriminatory features in true diffuse and focal uptake and any pitfalls.

\section{Method}

All 67-Ga scintigrams performed in a 1-year period up to September 1985 were considered for retrospective review. Fifty one patients had been studied, of whom 12 cases were not analysed either because the thorax had not been imaged at the time of scintigraphy or because notes or radiographs were unavailable.

Scintigraphy was performed using an IGE 400-T gamma camera interfaced to a computer. One hundred $\mathrm{MBq}$ of $67-\mathrm{Ga}$ were injected routinely, and images taken at 6, 24 and 48 hours. Ninety, 180 and $300 \mathrm{KeV}$ photo peaks were acquired simultaneously using a medium energy (up to $370 \mathrm{keV}$ maximum) parallel hole standard resolution collimator. Images were acquired for 400,000 counts.

Visual assessment was made of the 24 and 48 hour analogue images independently by 2 observers (PRG and SGC) without knowledge of the clinical or radiographic findings. The 6-hour images were reviewed but not scored due to the potential for variation in appearances consequent upon blood pool activity. Presence of pulmonary uptake (diffuse or 
focal) was noted and comparison made of activity over the cardiac and pulmonary areas on anterior and posterior scintigrams. Computer aided analysis was not performed. The notes and radiographs were subsequently reviewed to establish the accuracy of the scintigram interpretations. Diffuse pulmonary uptake was either:

(a) greater than the uptake seen over the cardiac area, when a 'negative heart' image was observed, (see Figure 1),

(b) less than that seen over the cardiac area, when the scintigram was considered negative for pulmonary uptake or

(c) seen equally over pulmonary and cardiac regions, i.e. there was no perceived visual difference between uptake over the lungs and the activity. seen over the cardiac area. This latter activity is produced partly by mediastinal structures but mainly from scatter arising from marrow uptake in sternum and vertebrae. Pulmonary activity would normally be expected to be lower than this. Thus this pattern of uptake was considered abnormal but the 'negative heart' sign was not seen as there was no difference in perceived intensity of uptake between the two reference areas. (d) Focal uptake in the lungs was assessed as being present when one or more discrete areas showed increased uptake compared with the adjacent pulmonary areas (see Figure 2).

\section{Results}

Thirty-nine cases with chest images recorded were analysed. Twelve cases (see Table I) had increased pulmonary accumulation of $67-\mathrm{Ga}$ and a 'negative heart' sign. In 6 cases this was due to diffuse uptake throughout the lungs (see Figure 1). In the remaining 6 cases the sign was caused by focal mediastinal or pulmonary uptake (see Figure 2). Four of the cases with diffuse pulmonary uptake had sarcoidosis or fibrosing alveolitis, one had adult respiratory distress syndrome and one miliary tuberculosis. One of the patients with focal uptake had sarcoidosis, and the remainder pulmonary consolidation due to infection ( 4 cases) or infarction ( 1 case), this latter case possibly being a septic infarct. ${ }^{8}$

The chest radiograph reflected the scintigram findings in 9 of these 12 cases. In the remaining three the radiograph was normal at the time of scintigraphy but became abnormal during the subsequent course of the patients' illness. In these cases the scintigram predicted the radiological outcome.

Seven cases (Table II) had abnormal 67-Ga scintigrams but without the 'negative heart' sign. Three had uniform (pulmonary and cardiac) uptake seen over the a

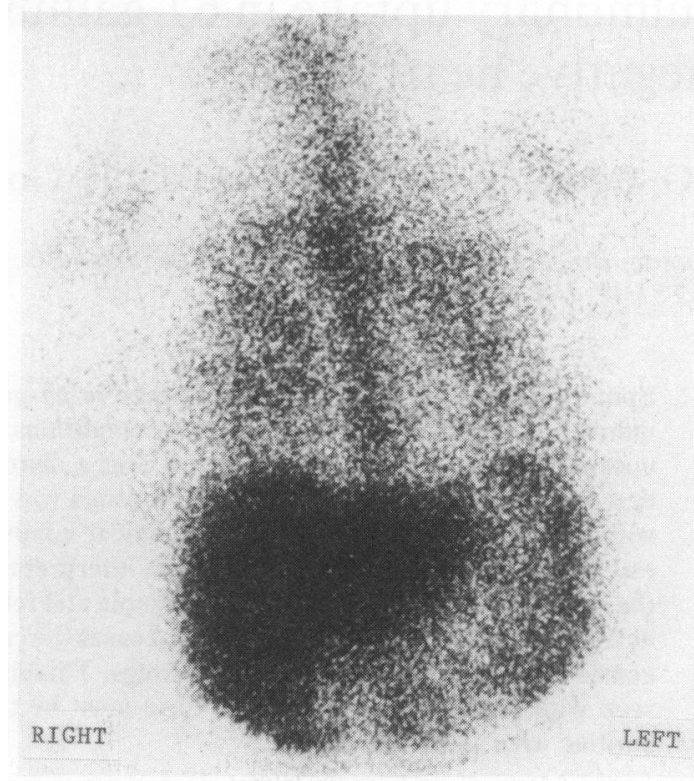

b

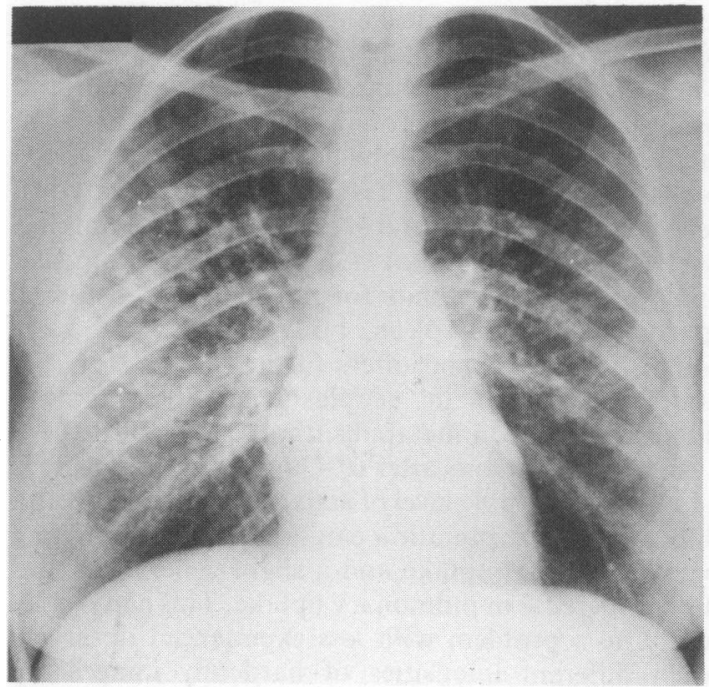

Figure 1 (a) Gallium scintigram (anterior view) showing diffusely increased pulmonary uptake relative to the cardiac area giving a 'negative heart' sign (case 6). (b) Chest radiograph of thesame patient showing widespread nodular opacities. Diagnosis: sarcoidosis. 
a

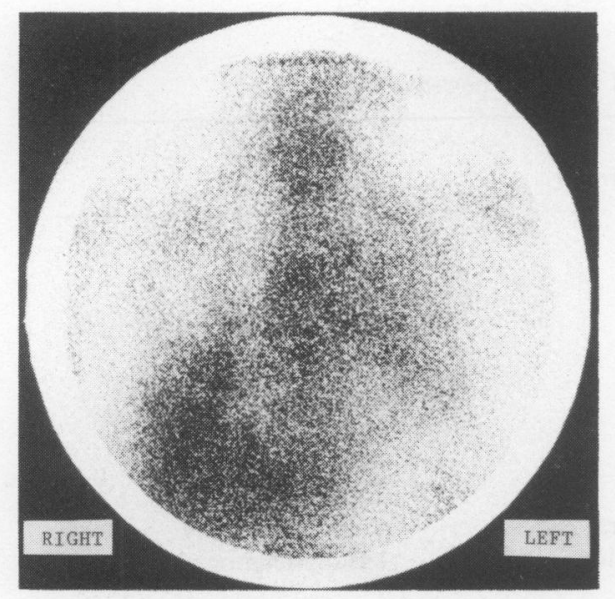

b

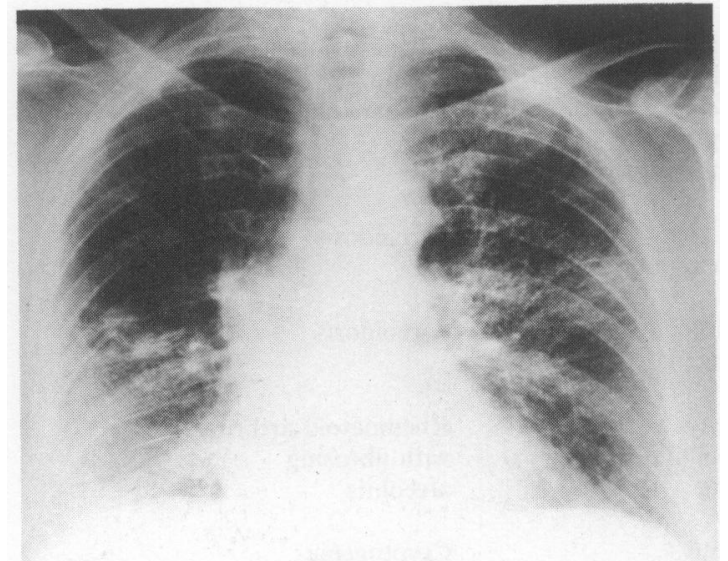

Figure 2 (a) Gallium scintigram (anterior view) showing focal increased pulmonary uptake at the right base and left perihilar regions. The less intense activity seen over the cardiac area produces a 'negative heart' sign (case 10). (b) The corresponding chest radiography shows reticulonodular and ring shadows in the left mid and right lower zones. Needle biopsy of the latter revealed lipoid pneumonitis.

chest, that is the activity seen over the lungs was at a similar level to that seen over the cardiac area/ mediastinum which we considered abnormal as discussed previously. Two of these were due to fibrosing alveolitis and the third multiple pulmonary metastases from carcinoma of the colon. Two cases had focal hilar uptake from sarcoidosis and the remaining two subdiaphragmatic uptake from hepatic and subphrenic abscesses respectively.
Twenty cases had a negative scintigram. Twelve of these were performed for suspected occult infection, 4 for the investigation of malignancy and the remainder to assess sarcoidosis. Subsequent clinical outcome has confirmed these negative scintigram interpretations with the following exceptions: one patient died from biliary peritonitis and gall bladder carcinoma 8 days after a negative scintigram and chest radiograph but bronchopneumonia was also found at post-mortem examination. A further patient with head injury subsequently died with aspiration pneumonia but from the clinical and radiographic evidence it is likely that the aspiration occurred after the $\mathrm{Ga}$ scintigram had been performed. Two patients had small pleural effusions due to pancreatitis and heart failure which were not identified by scintigraphy. Of the patients examined for sarcoidosis, 3 patients had ocular sarcoid only and the final diagnoses in two were revised to juvenile rheumatoid arthritis and hyperparathyroidism. Follow-up for one patient examined with sarcoidosis and for three other patients has unfortunately been unavailable but in all other cases the negative scintigram interpretations using our method were correct as judged by subsequent patient outcome.

\section{Observer variation in scintigram interpretation}

In 11 of the 12 cases with the 'negative heart' sign the two observers agreed on the initial scan interpretation (91\% concordance). Case 8 was reported by one observer (PRG) as diffuse increased uptake with a weak 'negative heart' sign and as uniform (pulmonary and cardiac) uptake by the second observer, that is, still abnormal but to a lesser degree.

In the absence of the 'negative heart' sign there was increased variation in scintigram interpretation between observers. This occurred particularly in cases of uniform (pulmonary and cardiac) uptake where there was agreement in interpretation in only one out of the three such cases. In the remaining 4 abnormal cases, one focal abnormality (case 14) was not initially reported as such by one observer giving an overall concordance of only $57 \%$ in abnormal cases without the 'negative heart' sign.

In the 20 cases that were considered normal there was disagreement in assessment in only one case, one observer commenting on an abnormal anterior chest image due to overlying breast uptake. Apart from with this case there was no subjective difference in image interpretation from anterior or posterior chest images although both of these views were analysed together. When the 'negative heart' sign was present it was visible on both views. 
Table I Abnormal gallium scintigrams with the 'negative heart' sign

\begin{tabular}{|c|c|c|c|c|c|}
\hline Case & Age & Sex & $\begin{array}{l}\text { Scintigram } \\
\text { abnormality }\end{array}$ & Chest radiograph & Diagnosis \\
\hline 1 & 58 & $\mathbf{F}$ & Diffuse & $\begin{array}{l}\text { Multiple } \\
\text { opacities }\end{array}$ & $\begin{array}{l}\text { Rheumatoid } \\
\text { arthritis } \\
\text { Adult respiratory } \\
\text { distress syndrome } \\
\text { associated with } \\
\text { sulphasalazine } \\
\text { therapy }\end{array}$ \\
\hline 2 & 64 & $\mathbf{M}$ & Multiple focal & $\begin{array}{l}\text { Small bilateral } \\
\text { pleural effusions }\end{array}$ & $\begin{array}{l}\text { Post-gastrectomy } \\
\text { basal pneumonia }\end{array}$ \\
\hline 3 & 76 & $\mathbf{F}$ & $\begin{array}{l}\text { Focal uptake } \\
\text { left chest }\end{array}$ & $\begin{array}{l}\text { Became abnormal* } \\
\text { with left lower } \\
\text { lobe consolidation }\end{array}$ & $\begin{array}{l}\text { Lobar pneumonia } \\
\text { Multiple metastases } \\
\text { (unknown primary) }\end{array}$ \\
\hline 4 & 70 & $\mathbf{F}$ & Diffuse & $\begin{array}{l}\text { Initially mild } \\
\text { heart failure } \\
\text { then developed* } \\
\text { cavitating lesions } \\
\text { with pleural effusions }\end{array}$ & $\begin{array}{l}\text { Congestive cardiac } \\
\text { failure } \\
\text { Miliary tuberculosis }\end{array}$ \\
\hline 5 & 38 & $\mathbf{M}$ & $\begin{array}{l}\text { Focal pulmonary } \\
\text { and mediastinal }\end{array}$ & $\begin{array}{l}\text { Bilateral hilar } \\
\text { lymphadenopathy }\end{array}$ & Sarcoidosis \\
\hline 6 & 59 & $\mathbf{F}$ & Diffuse & $\begin{array}{l}\text { Gross parenchymal } \\
\text { shadowing }\end{array}$ & Sarcoidosis \\
\hline 7 & 75 & $\mathbf{F}$ & Diffuse & $\begin{array}{l}\text { Widespread } \\
\text { reticulonodular } \\
\text { shadowing }\end{array}$ & $\begin{array}{l}\text { Rheumatoid arthritis } \\
\text { with fibrosing } \\
\text { alveolitis }\end{array}$ \\
\hline 8 & 68 & $\mathbf{M}$ & Diffuse & $\begin{array}{l}\text { Widespread } \\
\text { shadowing }\end{array}$ & $\begin{array}{l}\text { Cryptogenic } \\
\text { fibrosing alveolitis }\end{array}$ \\
\hline 9 & 74 & $\mathbf{F}$ & $\begin{array}{l}\text { Bilateral basal } \\
\text { focal }\end{array}$ & $\begin{array}{l}\text { Bilateral basal } \\
\text { infection or } \\
\text { infarction }\end{array}$ & $\begin{array}{l}\text { Retroperitoneal } \\
\text { fibrosis following } \\
\text { resection of } \\
\text { infiltrating rectal } \\
\text { carcinoma }\end{array}$ \\
\hline 10 & 60 & $\mathbf{M}$ & Focal basal & Basal shadowing & Lipoid pneumonia \\
\hline 11 & 56 & $\mathbf{F}$ & Diffuse & $\begin{array}{l}\text { Widespread } \\
\text { shadowing }\end{array}$ & $\begin{array}{l}\text { Cryptogenic } \\
\text { fibrosing alveolitis }\end{array}$ \\
\hline 12 & 59 & $\mathbf{M}$ & Focal & $\begin{array}{l}\text { Developed * left } \\
\text { mid-zone } \\
\text { consolidation }\end{array}$ & $\begin{array}{l}\text { Pancreatitis with } \\
\text { (probable) infected } \\
\text { pulmonary infarct }\end{array}$ \\
\hline
\end{tabular}

* Scintigram predicted radiological outcome 
Table II Abnormal gallium scintigrams but with no 'negative heart' sign

\begin{tabular}{|c|c|c|c|c|c|}
\hline Case & Age & $\operatorname{Sex}$ & $\begin{array}{l}\text { Scintigram } \\
\text { abnormality }\end{array}$ & Chest radiograph & Diagnosis \\
\hline 13 & 59 & $\mathbf{M}$ & Focal right basal & Pleural effusion & $\begin{array}{l}\text { Liver abscess } \\
\text { post biliary surgery }\end{array}$ \\
\hline 14 & 75 & $\mathbf{M}$ & Focal hilar & $\begin{array}{l}\text { Patchy shadowing } \\
\text { and fibrosis }\end{array}$ & Sarcoidosis \\
\hline 15 & 32 & $\mathbf{F}$ & Focal hilar & $\begin{array}{l}\text { Hilar and } \\
\text { paratracheal } \\
\text { lymphadenopathy }\end{array}$ & Sarcoidosis \\
\hline 16 & 62 & $\mathbf{M}$ & $\begin{array}{l}\text { Uniform intensity } \\
\text { (chest and heart) }\end{array}$ & Normal & $\begin{array}{l}\text { Cryptogenic } \\
\text { fibrosing alveolitis }\end{array}$ \\
\hline 17 & 60 & $\mathbf{M}$ & Focal basal & Pleural effusion & $\begin{array}{l}\text { Subphrenic abscess } \\
\text { post-gastrectomy }\end{array}$ \\
\hline 18 & 58 & F & $\begin{array}{l}\text { Uniform intensity } \\
\text { (chest and heart) }\end{array}$ & $\begin{array}{l}\text { Basal shadowing } \\
\text { (reticulonodular) }\end{array}$ & $\begin{array}{l}\text { Cryptogenic } \\
\text { fibrosing alveolitis }\end{array}$ \\
\hline 19 & 41 & $\mathbf{M}$ & $\begin{array}{l}\text { Uniform intensity } \\
\text { (chest and heart) }\end{array}$ & $\begin{array}{l}\text { Cannon ball } \\
\text { metastases }\end{array}$ & $\begin{array}{l}\text { Carcinoma of } \\
\text { colon }\end{array}$ \\
\hline
\end{tabular}

\section{Discussion}

The usefulness of 67-Ga scintigraphy in pulmonary diseases is well established, the extent of radionuclide accumulation correlating well with disease activity. $1,9,10$

Whilst several papers have discussed diffuse pulmonary uptake of $67-\mathrm{Ga}$, distinguishing between the normal slight diffuse pulmonary uptake and the abnormal can be difficult. Various methods have been suggested for evaluation of pulmonary uptake including comparing the activity to body background or liver, ${ }^{11,12}$ but this latter method assumes that the liver activity is normal which it may not be in a systemic disease such as sarcoidosis. ${ }^{13}$ Alternatively the liver activity may be abnormally reduced because of intense gallium avidity for a pathological process elsewhere. Most nuclear medicine departments now have data processing facilities and computer models have been devised to aid analysis ( $\mathrm{Ga}$ index). ${ }^{10,14}$ These are more lengthy and complicated to perform than inspection of analogue images, do not entirely eliminate interobserver variation and are limited by the data available. ${ }^{15,16}$ However, the computer aided methods of analysis may offer as an advantage the ability to quantitate an abnormality if serial scans for disease activity are contemplated. This is especially likely to be useful with scintigrams that are only equivocally abnormal. For the reasons already given the best of the described methods of computer aided analysis available involves comparison of pulmonary activity to a background reference of thigh activity. ${ }^{17}$

The observation of the 'negative heart' sign on 67-Ga chest images, whilst not completely eradicating some of the drawbacks already mentioned, is simple to perform and offers an easy, straightforward method for the identification of the clearly abnormal study. This is especially helpful to the less experienced observer. The sign is best produced by diffuse increased uptake throughout the lungs, but is also seen with focal pulmonary uptake. There is low $(<10 \%)$ interobserver variation in the interpretation of this sign.

Similar uptake over lungs to that seen over the cardiac area produces a uniform image which is identifiable from normal. However, this uniform abnormality is less striking than the 'negative heart' sign and less reliably interpreted. It can be difficult to distinguish from normal, variables such as breast uptake and rib scatter playing a part. Also, whether the three such cases in this study represent 'true positives' is not proven as neither of the cases with alveolitis had histological confirmation and the gallium avidity of the metastases in the third case is not proven. Uniform activity is therefore of uncertain significance without further analysis on the basis of this small study and should be interpreted with caution. 
Identification of abnormal focal uptake is not usually a problem, particularly if causing the 'negative heart' sign, but focal breast uptake should not be mistaken for abnormal pulmonary uptake. Overall, using our method of assessment the interobserver variation for all abnormal cases was $21 \%$, for normal cases $5 \%$ and for all cases $13 \%$. This compares favourably with other studies. ${ }^{15}$

One possible pitfall in assessing pulmonary $67-\mathrm{Ga}$ uptake by comparison with that over the cardiac area is if the uptake seen over the cardiac area itself is abnormal and more intense than the normal level of activity produced by mediastinal structures and marrow scatter. This might occur with myocardial sarcoidosis, an inflammatory cardiomyopathy or pericardial effusion, but we have not examined such a case in our institution. This may reflect case selection due to local clinical practice, other modalities being used to assess inflammatory cardiac disorders in lieu of $67-\mathrm{Ga}$ scintigraphy. Six-hour Ga scintigrams were also not formally analysed to avoid confusion with any low level activity in mediastinal structures that would be accounted for by blood pool activity.

A further possible pitfall is that the $67-\mathrm{Ga}$ scan may give a 'false negative' result if the patient is immunocompromised, on steroid or antibiotic therapy or is iron deficient. However, this is a limitation of the technique and will apply to any method of image interpretation as well as to our own.

The benefit of an absolute 'gold standard' in scan interpretation was not available for many of the patients and comparison with computer aided methods of analysis was not made. Reliance upon routinely available clinical parameters and patient

\section{References}

1. Bekerman, C., Hoffer, P.B., Bitram, J.D. \& Gupta, R.G. Gallium-67 citrate imaging studies of the lung. Semin Nucl Med 1980, X: 286-301.

2. Johnson, D.G., Johnson, S.M., Harris, C.C., Piantadosi, C.A., Blinder, R.A. \& Coleman, R.E. Gallium-67 uptake in the lung in sarcoidosis. Radiology 1984, 150: $551-555$.

3. Levenson, S.M., Warren, R.D., Richman, S.D., Johnston, G.S. \& Chabner, B.A. Abnormal pulmonary gallium accumulation in $P$. carinii pneumonia. Radiology 1976, 119: 395-398.

4. Stephton, R.G. \& Harris, A.W. Gallium-67 citrate uptake by cultured tumour cells stimulated by serum transferrin. JNCI 1975, 54: 1263-1266.

5. Tsan, M.F., Chen, W.Y. \& Scheffel, U. Mechanism of gallium localisation in inflammatory lesions. $J$ Nucl Med 1977, 18: 619.

6. Hartman, R.E. \& Hayes, R.L. The binding of gallium by the blood stream. J Pharmacol Exp Ther 1969, 168: $193-198$.

7. Hoffer, P.B., Huberty, J.P. \& Khyam Bashi, H. The association of 67-gallium and lactoferrin. $J \mathrm{Nucl} \mathrm{Med}$ 1977, 18: $713-717$. outcome was used in establishing whether the scintigram interpretations were correct. As already indicated, interpretation can be a problem with uniform (pulmonary and cardiac) uptake and we hypothesize that it is these cases that might benefit most from further computer aided analysis. In addition bronchoalveolar lavage may be used in further assessment, for example of the alveolitides following an equivocal scintigram, but this also is not an absolute standard and may be inferior to $67-\mathrm{Ga}$ scintigraphy in some cases. ${ }^{2}$ Open lung biopsy should be a suitable 'gold standard' for comparison but this is clearly not justified in routine clinical practice. It is possible that abnormal scintigrams may have been underdiagnosed in the normal group, although from the patients' subsequent clinical course there is no reason to believe this to be the case.

In conclusion, we believe that the observation of the 'negative heart' sign on analogue 67-Ga scintigram images of the chest is a useful, quick and reliable method of identifying abnormal studies in pulmonary disorders. It is seen in diffuse and focal pulmonary uptake. Care should be taken, as the sign may be masked, if uptake over the cardiac area itself is increased.

\section{Acknowledgements}

We thank the staff of the Organ Imaging Department, Bristol Royal Infirmary, the Department of Medical Illustration, Bristol Royal Infirmary and Miss Rachel Girling of PG Publications for secretarial assistance. We would also like to thank Dr G. Laszlo for his clinical assistance.

8. Niden, A.H., Mishkin, F.S., Khurana, M.M. et al. Gallium lung scan: an aid in the differential diagnosis of pulmonary embolism and pneumonitis. JAMA 1977, 237: $1206-1211$.

9. Siemsen, J.K., Grebe, S.F., Sargent, E.N. \& Wentz, E.D. Gallium-67 scintigraphy of pulmonary disease as a complement to radiography. Radiology 1976, 118: 371-375.

10. Line, B.R., Hunninglake, B.W., Keogh, B.A., Jones, E., Johnston, G.S. \& Crystal., R.G. Gallium-67 scanning to stage the alveolitis of sarcoidosis: correlation with clinical studies, pulmonary function studies and bronchoalveolar lavage. Am Rev Resp Dis 1981, 123: 440-446.

11. Siemsen, J.K., Sargent, E.N., Grebe, S.F. et al. Pulmonary concentration of $\mathrm{Ga} 67$ in pneumoconiosis. Am J Roentgenol 1974, 120: 815-820.

12. Siemsen, J.K., Grebe, S.F. \& Waxman, A.D. The use of gallium 67 in pulmonary disorders. Semin Nucl Med 1978, 3: $235-249$. 
13. Alberts C. \& van der Schoot, J.B. Standardized quantitative ${ }^{67} \mathrm{Ga}$ scintigraphy in pulmonary sarcoidosis. Sarcoidosis 1988, 5: 111-118.

14. Line, B.R., Fulmer, J.D., Reynolds, H.Y. et al. Gallium67 citrate scanning in the staging of idiopathic pulmonary fibrosis: correlation with physiologic and morphologic features and bronchoalveolar lavage. Am Rev Resp Dis 1978, 118: 355-365.

15. Fajman, W.A., Greenwald, L.V., Staton, G. et al. Assessing the activity of sarcoidosis: quantitative 67 Ga-citrate imaging. AJR 1984, 142: 683-688.
16. Bisson, G. Computer based quantitative analysis of 67 Ga uptake in normal and diseased lungs. Chest 1983, 5: 513-517.

17. McClean, R.G., Steele, P. \& Murray, I.P.C. Quantitation of pulmonary gallium-67 uptake: comparison of computer derived indices. Nucl Med Commun 1985, 6: 425-433. 